\title{
Antibodies to Chlamydia trachomatis in acute salpingitis
}

\author{
J. D. TREHARNE,* K. T. RIPA, † P-A. MÅRH,† L. SVENSSON, \\ L. WESTRÖM, $¥$ AND S. DAROUGAR* \\ From the *Virus Laboratory, WHO Collaborating Centre for Reference and Research on Trachoma \\ and other Chlamydial Infections, Institute of Ophthalmology, London; the †Institute of Medical \\ Microbiology, University of Lund; and the $\ddagger$ Department of Obstetrics and Gynaecology, \\ University Hospital, Lund, Sweden
}

SUMMARY Recent isolation studies have shown Chlamydia trachomatis to be an important aetiological agent in acute salpingitis in women. The present serological study indicates that $C$. trachomatis is the probable aetiological agent in two-thirds of 143 women with pelvic inflammatory disease (PID). In general, high levels of chlamydial antibody were found in sera and fluids aspirated from the pouch of Douglas and such antibody titres were shown to correlate with the severity of clinically graded tubal inflammation.

\section{Introduction}

The sequelae of acute salpingitis (pelvic inflammatory disease, PID) are the most common cause of infertility in women (Weström, 1975).

Several different micro-organisms have been implicated as the cause of PID, suggesting that the disease has a polymicrobial aetiology (Eschenbach et al., 1975).

The vast majority of cases of acute salpingitis are caused by micro-organisms that have colonised or infected the cervix or both and reached the tubes as the result of an ascending infection (Falk, 1946; Danielsson et al., 1975).

Although Neisseria gonorrhoeae has often been considered the major cause of this disease, Mårdh et al. (1977a) could recover the organism in only approximately one out of 10 patients with acute salpingitis and cervical gonorrhoea. Furthermore, recent culture studies have shown that over $30 \%$ of cases of PID may be due to Chlamydia trachomatis (Mårdh et al., 1977b). In these patients with PID, who harboured chlamydiae in the cervix, the organism was recovered from the uterine tubes in six out of seven cases.

In the present study, in which we used the modified micro-immunofluorescence test (Treharne et

Address for reprints: J. D. Treharne, Virus Laboratory, Institute of Ophthalmology, Judd Street, London WC1H 9QS

Received for publication 26 June 1978 al., 1977a), we aim to assess the level and prevalence of different immunoglobulin classes of type specific chlamydial antibodies in sera and in fluid aspirated from the pouch of Douglas in a series of women with laparoscopically verified acute salpingitis and to present the findings in relation to the visual clinical grading of tubal inflammation.

\section{Material and methods}

PATIENTS

Since 1960, diagnostic laparoscopy has been performed on all patients with the presumptive diagnosis of acute salpingitis admitted to the department of obstetrics and gynaecology at the University Hospital, Lund, Sweden (Weström and Mårdh, 1977). This study included patients examined at this clinic during a period between 1973 and 1977.

Laparoscopy was carried out on the day of admission of each patient. The laparoscopic technique and the criteria of a laparoscopic diagnosis of acute salpingitis have been described in detail elsewhere (Jacobson and Weström, 1969). The inflammatory changes of the fallopian tubes, as seen at laparoscopy, were graded as mild (reddened serosa of the tubes, oedema of the tubal wall, and purulent discharge from the abdominal orifice), moderate (more advanced inflammatory changes confined to the tubes, such as tubal swelling, closure of the abdominal orifices, and fibrin deposits 
on the serosal surfaces of the tubes), or severe (pelvic peritonitis or abscess formation).

\section{COLLECTION OF SPECIMENS}

Serum samples were collected on the day of admission from 143 women with acute salpingitis. During laparoscopy, peritoneal fluid from 27 patients was aspirated from the pouch of Douglas by means of a canula inserted through a separate incision in the abdominal wall (Mardh et al., 1977b). Serum samples were also collected from an additional 19 women who had no signs of genital infection and who had been laparoscoped.

\section{SERODIAGNOSTIC PROCEDURES}

Antibodies to chlamydiae were detected by means of a modified micro-immunofluorescence test using pooled chlamydial antigens (Treharne et al., 1977b). All sera and aspirates from the pouch of Douglas were stored for varying periods of time at $-20^{\circ} \mathrm{C}$ before being tested for different immunoglobulin classes of chlamydial antibodies.

\section{Results}

Eighty-eight out of $143(62 \%)$ patients with acute salpingitis had chlamydial IgG antibody levels of $1 / 64$ or greater in their sera (Table 1). The geometric mean titre (GMT) of antibody in all 143 women was $1 / 51$.

The results indicate that there is a correlation between the inflammatory grade of salpingitis, the percentage of women with high levels of IgG chlamydial antibody (that is, $\geqslant 1 / 64$ ), and the GMT of their antibody. Thus a high percentage of women $(73 \%)$ with severe salpingitis-that is, pelvic peritonitis or abscesses-has significant levels of antibody and also the highest GMT of chlamydial IgG antibody (1/527). In contrast, of the other 19 women with no salpingitis only two showed high levels of antibody. The overall GMT of antibody in this control group was $1 / 2$.
Table 2 Levels of IgM chlamydial antibody in 142 women with acute salpingitis

\begin{tabular}{llll}
\hline & $\begin{array}{l}\text { No. of } \\
\text { patients }\end{array}$ & $\begin{array}{l}\text { With IgM } \\
(\%)\end{array}$ & $\begin{array}{l}\text { GMT of IgM } \\
\text { antibody }\end{array}$ \\
\hline $\begin{array}{llll}\text { Grade of salpingitis } \\
\quad \text { Mild }\end{array}$ & 52 & 17 & $1 / 15$ \\
Moderate & 61 & 28 & $1 / 24$ \\
$\quad$ Severe & 29 & 21 & $1 / 58$ \\
Totals & 142 & 23 & $1 / 25$ \\
Controls & 19 & 5 & - \\
\hline
\end{tabular}

The sera of all but one of the 143 women were also examined for the presence of chlamydial IgM antibody (Table 2$)$. In only $33(23 \%)$ out of these 142 women could IgM chlamydial antibody be detected. Although there appeared to be a correlation between the grade of tubal inflammation and the GMT of IgM antibody, no such correlation could be shown with the percentage of women in whom IgM chlamydial antibody was detected.

Fluid aspirated from the pouch of Douglas in 27 women with acute salpingitis had high GMTs of both IgG and IgA chlamydial antibody (Table 3 ). Once again the GMTs and the percentage of women having high levels of IgG antibody increased with increasing severity of tubal inflammation.

In six women from whom sera and fluid aspirates from the pouch of Douglas were obtained (Table 4) the IgG and $\operatorname{IgA}$ chlamydial antibody levels were similar in both sets of specimens except in one patient (case 5), in whom very much higher levels of IgG and IgA chlamydial antibody were detected in the fluid aspirated from the pouch of Douglas.

In 83 out of 88 women in whom IgG chlamydial antibody was demonstrated, the predominant type-specific antibody was of the paratrachoma (D through to $\mathrm{K}$ ) serotypes. No attempt was made to identify the particular serotype responsible, except in the remaining five patients with salpingitis, in whom the predominant type-specific chlamydial antibody was of the $\mathrm{C} / \mathrm{J}$ type.

Table 1 Distribution of IgG chlamydial antibody titres in sera from 143 women with acute salpingitis

\begin{tabular}{|c|c|c|c|c|c|c|c|c|c|c|c|c|c|c|c|}
\hline & \multirow[b]{2}{*}{$\begin{array}{l}\text { No. of } \\
\text { patients }\end{array}$} & \multicolumn{11}{|c|}{ Reciprocal IgG chlamydial antibody titres } & \multirow[b]{2}{*}{$\begin{array}{l}\text { With } \\
\geqslant 1 / 64(\%)\end{array}$} & \multicolumn{2}{|c|}{ Geometric mean titre } \\
\hline & & $<16$ & 16 & 32 & 64 & 128 & 256 & 512 & 1024 & 2048 & 4096 & 8192 & & All patients & $\begin{array}{l}\text { Patients with } \\
\text { IgG antibody }\end{array}$ \\
\hline \multicolumn{16}{|c|}{ Grade of salpingitis } \\
\hline Mild & 52 & 14 & 4 & 11 & 12 & 5 & 5 & 1 & $\mathbf{0}$ & 0 & 0 & $\mathbf{0}$ & 43 & $1 / 21$ & $1 / 63$ \\
\hline Moderate & 61 & 11 & 4 & 3 & 10 & 10 & 10 & 5 & 3 & 0 & 3 & 2 & 68 & $1 / 73$ & $1 / 189$ \\
\hline Severe & 30 & 7 & 0 & 1 & 3 & 0 & 7 & 4 & 5 & 2 & 1 & $\overline{0}$ & 73 & $1 / 122$ & $1 / 527$ \\
\hline Total & 143 & 32 & 8 & 15 & 25 & 15 & 22 & 10 & 8 & 2 & 4 & 2 & 62 & $1 / 51$ & $1 / 160$ \\
\hline Controls & 19 & 15 & 2 & 0 & 0 & 1 & 1 & 0 & 0 & $\overline{0}$ & 0 & $\overline{0}$ & $10 \cdot 5$ & $1 / 2$ & $1 / 54$ \\
\hline
\end{tabular}


Table 3 Distribution of $\operatorname{IgG}$ and IgA chlamydial antibody titres in fluid aspirated from the pouch of Douglas in 27 women with salpingitis

\begin{tabular}{|c|c|c|c|c|c|c|c|c|c|c|c|c|c|c|c|c|c|c|}
\hline & \multirow{2}{*}{$\begin{array}{l}\text { No. of } \\
\text { patients }\end{array}$} & \multirow{2}{*}{$\begin{array}{l}\text { Immuno- } \\
\text { globulin }\end{array}$} & \multicolumn{13}{|c|}{ Reciprocal chlamydial antibody titres } & \multirow{2}{*}{$\begin{array}{l}\text { With IgG } \\
\geqslant 1 / 64(\%)\end{array}$} & \multicolumn{2}{|c|}{$\begin{array}{l}\text { GMT of } \\
\text { chlamydial } \\
\text { antibodies }\end{array}$} \\
\hline & & & $<8$ & 8 & 16 & 32 & 64 & 128 & 256 & 512 & 1024 & 2048 & 4096 & 8192 & 16384 & & $I g G$ & $\operatorname{Ig} A$ \\
\hline \multicolumn{19}{|c|}{$\begin{array}{l}\text { Grade of } \\
\text { salpingitis }\end{array}$} \\
\hline \multirow[t]{2}{*}{ Mild } & 12 & IgG & 1 & ND & 0 & 5 & 1 & 1 & 1 & 1 & 1 & 0 & 1 & 0 & 0 & 50 & $1 / 128$ & - \\
\hline & & IgA & 6 & 0 & 2 & 1 & 2 & 0 & 1 & 0 & 0 & 0 & 0 & 0 & 0 & - & - & $1 / 45$ \\
\hline \multirow[t]{2}{*}{ Moderate } & 10 & IgG & 0 & ND & 1 & 1 & 0 & 2 & 1 & 2 & 0 & 1 & 0 & 1 & 1 & 80 & $1 / 338$ & - \\
\hline & & IgA & 3 & 2 & 0 & 1 & 1 & 1 & 0 & 1 & 1 & 0 & 0 & 0 & 0 & - & - & $1 / 71$ \\
\hline \multirow[t]{2}{*}{ Severe } & 5 & IgG & 1 & ND & 0 & 0 & 0 & 1 & 0 & 0 & 0 & 1 & 1 & 1 & 0 & 80 & $1 / 1721$ & - \\
\hline & & IgA & 3 & 0 & 0 & 0 & 1 & 1 & 0 & 0 & 0 & 0 & 0 & 0 & 0 & - & - & $1 / 90$ \\
\hline Totals & 27 & IgG & 2 & ND & 1 & 6 & 1 & 4 & 2 & 3 & 1 & 2 & 2 & 2 & 1 & 67 & $1 / 285$ & - \\
\hline Totals & 27 & IgA & 12 & 2 & 2 & 2 & 4 & 2 & 1 & 1 & 1 & 0 & 0 & 0 & 0 & - & 一 & $1 / 61$ \\
\hline
\end{tabular}

ND Not done

Table 4 Chlamydial antibody titres in matched sera and fluids aspirated from the pouch of Douglas in six women with acute salpingitis

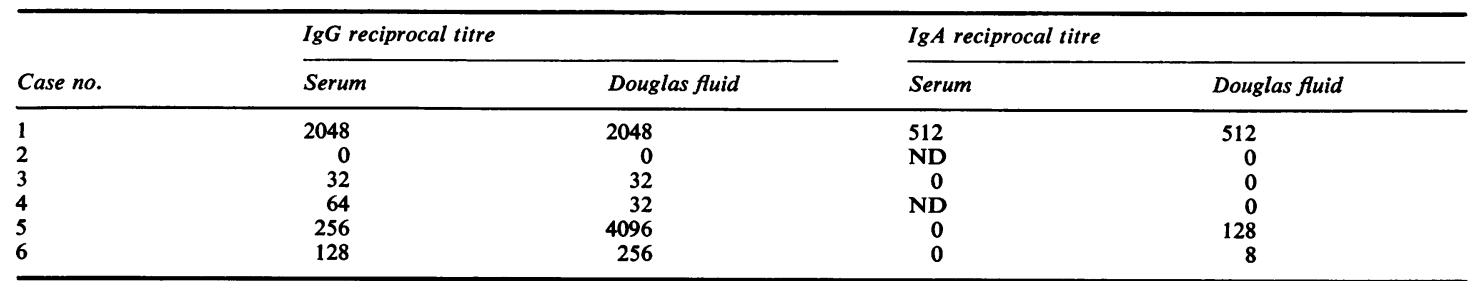

ND Not done

\section{Discussion}

In Sweden, since 1970, the annual number of reported cases of gonorrhoea has decreased by over $30 \%$. During this period, a corresponding decrease in the number of diagnosed cases of PID with gonococcal infection of the cervix has occurred. The total incidence of PID during this same period, however, has increased (Weström and Mårdh), 1975). During the period 1975 to 1977 gonococci could be isolated from the cervix of $10-20 \%$ of women with PID in southern Sweden, whereas during the same period $C$. trachomatis was isolated in about $33 \%$ of a series of patients with acute salpingitis (Mårdh et al., 1977b).

Laparoscopy offers a means for visual inspection of pelvic organs and thus makes it possible not only to diagnose acute salpingitis accurately but also to collect specimens for culture directly from the fallopian tubes.

A simple serodiagnostic test for the detection of type-specific chlamydial antibody has recently been described (Treharne et al., 1977a). In addition to indicating the predominant type-specific antibody the test can also identify the immunoglobulin class of antibody. The authors showed that women with proved chlamydial cervicitis had a GMT of
IgG antibody of $1 / 64$ or more. Mårdh et al. (1977a), using a similar test in two patients with acute salpingitis in whom $C$. trachomatis had been isolated from the fallopian tubes, also showed that high titres of IgG chlamydial antibodies could be detected.

Of 143 women with acute salpingitis described in this present series $62 \%$ had IgG chlamydial antibody levels of $1 / 64$ or greater, which we suggest is indicative of an active infection with $C$. trachomatis. Furthermore, only $10.5 \%$ of the control group of 19 women showed such levels of antibody, the GMT of all these women being only $1 / 2$. The IgG GMT in the group of women with PID correlated well with the intensity of tubal inflammation, the highest GMT of antibody being found in women with the most severe grade of salpingitis. This pattern of higher GMTs being associated with most severe PID was also found when IgM chlamydial antibody was detected. There was, however, no correlation between the percentage of women having IgM chlamydial antibody and the grade of tubal inflammation as judged by the laparoscopy findings. Overall, only $23 \%$ (33 out of 142) of patients had any level of IgM chlamydial antibody. The possible explanation for this finding could be that, as infection of the fallopian tubes is preceded 
by cervical infection, it is unlikely that the transiently present IgM antibody would have persisted in the patients with acute salpingitis. There is evidence to suggest that in $C$. trachomatis oculo-genital infections with serotypes generally encountered in genital infections IgM chlamydial antibody persists for about eight to 10 weeks (Treharne et al., unpublished data). Also, the sera from most patients with salpingitis studied had been stored for one to four years before being tested, during which time the relatively labile IgM antibody may have been denatured. Finally, in women developing salpingitis repeated infection with $C$. trachomatis agent may occur, which, if of the same serotype, would apparently result in no recall of the IgM antibody produced during the previous infection (Wang and Grayston, 1971).

The very high GMT of IgG chlamydial antibody $(1 / 285)$ in fluid aspirated from the pouch of Douglas in two-thirds of the women with PID is strongly suggestive of chlamydial infection. In women with no salpingitis, only two out of nine tested-both of whom had lower genital tract infection-showed any evidence of chlamydial antibody in fluid aspirated from the pouch of Douglas.

Evidence from matched serum and fluid aspirated from the pouch of Douglas in one (Case 5) of the six patients tested suggested that not all the IgG and IgA chlamydial antibody found in fluid aspirates is derived by transudation from the serum but that some may have been produced locally. Indications of local chlamydial antibody have also been shown in cervical secretions from women with cervicitis (Treharne et al., 1978).

Previous studies (Treharne et al., 1977b) showed that mothers of babies with proved ophthalmia neonatorum due to $C$. trachomatis had geometric mean chlamydial antibody titres of $1 / 122$. Dunlop et al. (1967) suggested that salpingitis occurs in such women. The patients with salpingitis studied, apart from a group of patients with classical lymphogranuloma venereum and infants with chlamydial pneumonia (Beem and Saxon, 1977), have had the highest levels of antibody of any group of patients with proved $C$. trachomatis infection.

This study, based on serodiagnostic and clinical criteria, indicates that $C$. trachomatis is the probable aetiological agent in as many as $66 \%$ of women with acute salpingitis.

The authors are grateful to Professor Barrie R. Jones for his advice and encouragement and to
Mr R. J. Dines and Miss C. Renström for their excellent technical assistance. We are indebted to an anonymous donor and a grant (16X-04509) from the Swedish Medical Research Council for financial support of this collaborative project.

\section{References}

Beem, M. O., and Saxon, E. M. (1977). Respiratory tract colonization and a distinctive pneumonia syndrome in infants infected with Chlamydia trachomatis. New England Journal of Medicine, 296, 306-310.

Danielsson, D., Falk, V., and Forslin, L. (1975). Acute salpingitis and gonorrhoea on a gynaecological ward. In Genital Infections and their Complications, pp 151-156. Edited by D. Danielsson, L. Juhlin, P-A. Mårdh. Almqvist and Wiksell International: Stockholm.

Dunlop, E. M. C., Freedman, A., Garland, J. A., Harper, I. A., Jones, B. R., Race, J. W., Du Toit, M. S., and Treharne, J. D. (1967). Infection by Bedsoniae and the possibility of spurious isolation: 2. Genital infection, disease of the eye, Reiter's disease. American Journal of Ophthalmology, 63, 1073-1081.

Eschenbach, D. A., Buchanan, T. M., Pollock, H. M., Forsyth, P. S., Alexander, E. R., Lin, J-S., Wang, S-P., Wentworth, B. B., McCormack, W. M., and Holmes, K. K. (1975). Polymicrobia aetiology of acute pelvic inflammatory disease. New England Journal of Medicine, 293, 166-171.

Falk, H. C. (1946). Interpretation of the pathogenesis of pelvic infection as determined by corunal resection. American Journal of Obstetrics and Gynecology, 52, 66-73.

Jacobson, L., and Weström, L. (1969). Objectivized diagnosis of acute pelvic inflammatory disease: diagnostic and prognostic value of routine laparoscopy. American Journal of Obstetrics and Gynecology, 105, 1088-1098.

Mårdh, P-A., Ripa, K. T., Wang, S-P., and Weström, L. (1977a) Chlamydia trachomatis as an aetiological agent in acute salpingitis. In Non-gonococcal Urethritis and Related Oculogenital Infections, pp 77-83. Edited by K. K. Holmes and D. Hobson. American Society for Microbiology: Washington DC.

Måríh, P-A., Ripa, K. T., Svensson, L., and Weström, L. (1977b). Chlamydia trachomatis infection in patients with acute salpingitis. New England Journal of Medicine, 296, 1377-1379.

Treharne, J. D., Darougar, S., and Jones, B. R. (1977a). Modification of the microimmunofluorescence test to provide a routine serodiagnostic test for chlamydial infection. Journal of Clinical Pathology, 30, 510-517.

Treharne, J. D., Darougar, S. D., Simmons, P. D., and Thin, R. N. (1978). Rapid diagnosis of chlamydial infection of the cervix. British Journal of Venereal Diseases, 54, 403-408.

Treharne, J. D., Dines, R. J., and Darougar, S. (1977b). Serological responses to chlamydial ocular and genital infections in the United Kingdom and Middle East. In Non-gonococcal Urethritis and Related Infections, pp 249-258. Edited by K. Holmes and D. Hobson. American Society for Microbiology: Washington DC.

Wang, S-P., and Grayston, J. T. (1971). Local and systemic antibody response to trachoma infection in monkeys. In Trachoma and Related Disorders, pp 217-232. Edited by R. L. Nicols. Excerpta Medica: Amsterdam.

Weström, L. (1975). Effect of acute pelvic inflammatory disease on fertility. American Journal of Obstetrics and Gynecology, 121, 707-713.

Weström, L., and Márdh, P-A. (1975). Acute salpingitis: aspects on aetiology, diagnosis, and prognosis. In Genital Infections and their Complications, pp 157-167. Edited by D. Danielsson, L. Juhlin, P-A. Mårdh. Almqvist and Wiksell International: Stockholm.

Weström, L., and Mårdh, P-A. (1977). Epidemiology, etiology, and prognosis of acute salpingitis: A study of 1,457 laparoscopically verified cases. In Non-gonococcal Urethritis and Related Infections, pp 84-90. Edited by K. Holmes and D. Hobson. American Society for Microbiology: Washington DC. 